\title{
EDITORIAL \\ Glasgow encounters with tropical diseases
}

\author{
FRANCIS E. G. COX* \\ London School of Hygiene and Tropical Medicine, Keppel Street, London WC1E 7HT, UK
}

(Received 17 May 2017; accepted 21 May 2017; first published online 4 Fuly 2017)

\begin{abstract}
SUMMARY
The period 1875-1925 was remarkable in the history of parasitology mainly for the elucidation of the life cycles of parasites causing important parasitic diseases and the incrimination of vectors in their transmission. These discoveries were made by a small number of scientists working in the tropics a number of whom were Scots. Sir Patrick Manson, the discoverer of the mosquito transmission of filarial worms, was instrumental in directly or indirectly encouraging other Scots including Douglas Argyll-Robertson, David Blacklock, David Bruce, David Cunningham, Robert Leiper, William Leishman, George Low, Muriel Robertson and Ronald Ross, who all made significant discoveries across a wide spectrum of tropical diseases. Among these, William Leishman, Robert Leiper and Muriel Robertson were all graduates of the University of Glasgow and their achievements in the fields of leishmaniasis, schistosomiasis, dracunculiasis and African sleeping sickness, together with subsequent developments in these fields, are the subjects of the ten papers in this Special Issue of Parasitology.
\end{abstract}

Key words: Livingstone, Leishman, Leiper, Robertson, leishmaniasis, trypanosomiasis, schistosomiasis, Guinea worm disease.

\section{INTRODUCTION}

The period 1875-1925, often referred to as the golden age of parasitology, or sometimes more accurately the golden age of descriptive parasitology, was remarkable in the history of parasitology mainly for the elucidation of the life cycles of parasites causing important parasitic diseases and the incrimination of vectors in their transmission. These discoveries opened up new avenues for the control of parasitic diseases and set in motion measures that we rely on today. These discoveries were made by a small number of scientists working in Europe, the USA and the tropics, many of whom contributed to several different fields. A disproportionate number of these individuals were Scots: Sir Patrick Manson, 'the father of tropical medicine' who discovered the mosquito transmission of filarial worms, was instrumental in directly or indirectly encouraging others including Douglas ArgyllRobertson, David Blacklock, David Bruce, David Cunningham, Robert Leiper, William Leishman, George Low, Muriel Robertson and Ronald Ross, who all made significant discoveries across a wide spectrum of tropical diseases. Among these, William Leishman, Robert Leiper and Muriel Robertson were all graduates of the University of Glasgow and their contributions to our understanding of tropical diseases was the subject of a Symposium, Glasgow Encounters with Tropical Diseases, held in Glasgow in January 2016. The

* Corresponding author: Francis E. G. Cox, 7, Chessington Road, Epsom, Surrey KT17 1TS, UK. E-mail: Francis. cox1@btinternet.com ten papers in this Special Issue celebrate their achievements and discuss and evaluate some of the current advances in our understanding of the diseases in which they were pioneers.

The first paper, The golden age of Parasitology (Cox, 2017a), paints a broad brush picture of the achievements of the ten Scottish scientists listed above in their particular fields of endeavour: Argyll-Robertson (loiasis), Blacklock (onchocerciasis), Bruce (African trypanosomiasis), Cunningham (leishmaniasis), Leiper (schistosomiasis and dracunculiasis), Leishman (leishmaniasis), Low (filariasis), Manson (filariasis, loiasis, onchocerciasis and malaria), Robertson (African trypanosomiasis) and Ross (malaria and leishmaniasis) together with brief biographies. The interactions between these individuals, and the pivotal role played by Manson, is discussed in the context of the roles played by generations of Scottish doctors who, served in the army or Colonial civil service, particularly in the tropics, where they first became aware of the 'exotic diseases' prevalent in tropical climates and stimulated research into the medical and social problems that these diseases caused. The conclusion reached in this chapter is that the need to determine parasite life cycles, and the role of vectors, was very much focused on the ideals of Empire particularly the prevention of disease among the troops and expatriate civil servants and, only later, local civil servants and the native populations as a whole. This Special Issue celebrates the achievements of the three Glasgow scientists, William Leishman, Muriel Robertson and Robert Leiper, and also considers current developments in the fields that they pioneered. 
WILLIAM BOOG LEISHMAN

William Boog Leishman (1865-1926), a medical officer in the British army, best known for his discovery of the parasitic cause of kala azar, Leishmania donovani, and the invention of a method for staining blood slides, Leishman's stain, which now commemorate his name also made major contributions in the fields of typhoid and public health and these achievements are the subject of a paper by Heather Vincent in this issue (2017). While serving in India, he became interested in diseases affecting British troops and spent some time working at the Dum Dum station in Calcutta where he encountered patients suffering from kala azar (locally known as Dumdum fever) the cause of which was unknown and was suspected to be a form of malaria or possibly typhoid. Leishman returned to Britain in 1897 and took up the post of assistant to Almoth Wright at the Army Medical College at Netley near Southampton where he had access to blood and tissues of repatriated soldiers. In 1900, while looking for malaria parasites in blood films from patients suffering from kala azar and, facilitated by his invention of Leishman's stain, he observed novel bodies that we now know to be the amastigote forms of Leishmania donovani. Leishman meticulously recorded his observations but it was not until 1903 that he began to suspect that the parasites that he had observed might be related to trypanosomes (Leishman, 1903). In the same year, Charles Donovan found similar bodies in patients with cutaneous lesions (Donovan, 1903). Ronald Ross recognised that both workers had observed the same kinds of organisms and that these were the causative organisms of both kala azar and cutaneous leishmaniasis and coined the name of Leishman-Donovan bodies for the structures they had seen (Ross, 1903).

As well as the discovery of the parasite named after him, Leishman's contribution to public health, particularly typhoid, was even more important. His interest in typhoid began when the British Government realised that typhoid was a major cause of morbidity and mortality among British troops. Leishman was charged with investigating this problem and, with his understanding of immunity gleaned from his association with Almoth Wright, demonstrated the efficacy of anti typhoid inoculation. He later used his considerable political skills to advocate the vaccination of troops in an emergency so, when the First World War broke out in 1914, British troops had the advantage over the Germans troops of having been vaccinated. Subsequently the vaccine saved thousands of military and civilian lives.

MURIEL ROBERTSON

The achievements of the second Glasgow graduate, Muriel Robertson (1883-1973), are discussed by
Tansy Hammarton (2017). Muriel Robertson, the only woman in this pantheon of Scottish scientists, was a protozoologist who made major contributions in the fields of protozoology, bacteriology and immunology. Shortly after graduating, Robertson joined the Lister Institute in London under the direction of the distinguished protozoologist, Edwin Minchin. A year later, with no experience with tropical diseases, she joined an expedition to Uganda to investigate an outbreak of sleeping sickness and there she developed an interest in the trypanosome parasites and their tsetse fly vectors, an interest that she pursued in London after her return to the Lister Institute. African trypanosomiases, sleeping sickness in humans and nagana, in cattle are ancient diseases but their causes and mode of transmission remained unknown until 1894 when David Bruce, a Scot then working as a British Colonial Medical Officer, was sent to South Africa to investigate an outbreak of nagana, as it was known by the local people, and 'fly disease' by hunters and travellers. Bruce found organisms in the blood of diseased cattle that resembled the trypanosome (Trypanosoma evansi) previously recorded from horses and deduced that these trypanosomes, now known to be Trypanosoma brucei brucei, were the cause of nagana and conclusively demonstrated that trypanosomes were transmitted by tsetse flies (Bruce, 1894) but thought that transmission was purely mechanical (Bruce, 1915). The role of the tsetse fly in the biological transmission of the African trypanosomes was determined by Friedrich Kleine, a colleague of Robert Koch, who demonstrated cyclical transmission but mistakenly thought that there was a sexual stage in the life cycle (See Hoare, 1972). This error was not surprising because trypanosomes in the blood occur in two forms, short stumpy and long thin. Bruce and Robertson, both working in London, were intrigued by this phenomenon and subscribed to the two sex hypothesis and suggested that the slender forms were males and the stumpy forms females. Robertson soon realised that the two forms were actually successive stages in the same life cycle and that only the slender forms were able to divide and surmised that the stumpy forms were the stages infective to tsetse flies and abandoned her earlier theory. Armed with this knowledge, Robertson began a meticulous study of the fate of Trypanosoma congolense, another trypanosome parasite of cattle, and her 1913 detailed descriptions of the development of trypanosomes from being taken up from the blood to the infective stages in the tsetse proboscis, including their circuitous route via the endoperitrophic space, remains essentially the same today (Robertson, 1913). Bruce was fulsome in his praise for Robertson and considered that she has done some of the best work in this branch of protozoology. 
Robert Bruce had also observed that the trypanosomes in the blood of cattle persisted for some time and that the numbers of parasites in the blood fluctuated considerably over time. This phenomenon was subsequently recorded by several authors including Ronald Ross and David Thompson (1911). Bruce was unable to follow up his initial observations, which were largely ignored until Muriel Robertson began to look at the problem again and followed up her earlier observations that there were two forms of trypanosomes in the blood, long slender forms that divided and short stumpy forms that did not and were infective to tsetse flies. She noted that the first forms that appeared in the blood were the long slender dividing forms and that they appeared as waves in the blood, sometimes completely disappearing, and postulated that there was some 'tension' between the host's ability to destroy the parasite and the capacity of the parasite to maintain itself (Robertson, 1912). Robertson got tantalisingly close to establishing that it was the immune response that was responsible for the fluctuating parasitaemias but facilities to pursue this further were not available at that time. Subsequently, with the availability of the electron microscope and new cytological techniques, it gradually became clear that the cause of the fluctuating parasitaemias was antigenic variation, and that the trypanosome protein coat was the variant antigen as discovered by Keith Vickerman later Regius Professor of Zoology in the University of Glasgow in the 1960s (Vickerman and Luckins, 1969).

Thus, over a short period from 1912 to 1913 Robertson produced a series of papers concerned with the development of several species of trypanosomes in tsetse flies that remain classics until the present day. Robertson's work on trypanosomes was interrupted by the outbreak of the First World War when she was directed to work on anaerobic bacterial infections, particularly clostridial, in war wounds. In order to do this she devised new culture techniques and biochemical assays and developed serological tests to distinguish between different serotypes of Clostridium. She also tried, unsuccessfully, to develop a vaccine against Clostridium perfringens. As well as her work on anaerobic bacteria, she also tried to identify the cause of typhus.

It was some time after the end of the war until Robertson once again turned her attention to the study of kinetoplastid flagellates, especially the freshwater oganism Bodo caudatus, and made detailed studies of nuclear division and the nature of the kinetoplast, observations that are relevant today and the basis of many subsequent studies by other scientists. In 1938, Roberson again changed her choice of organism with which to work and chose Trichomonas foetus, now known to cause serious disease resulting in abortion in cattle but then thought to be merely a commensal. Robertson became interested in the immunology of the disease and diagnostic methods and was one of the first protozoologists to be regarded as an immunologist. Robertson continued her work at Cambridge until well into her 70 s.

ROBERT THOMPDON LEIPER AND

SCHISTOSOMIASIS

The next three contributions to this Symposium are concerned with schistosomiasis from early history to current attempts to control the disease. Human schistosomiasis, or bilharzia, is caused by several species of Schistosoma, particularly Schistosoma mansoni, the intestinal form, Schistosoma haematobium, the urinary form, and Schistosoma japonicum the Asiatic form. Adult worms of S. haematobium, were first discovered by Theodor Bilharz in1851 (Bilharz, 1853) and, for some years afterwards, it was thought that this species was responsible for both intestinal and urinary manifestations of the disease in Africa. In 1902, Manson found a different kind of schistosome egg and postulated that there are two species of Schistosoma in humans, one, with eggs with lateral spines, responsible for the intestinal form of the disease, and the other, with terminal spines, the urinary form. Unable to pursue this problem himself, Manson was instrumental in sending Robert Leiper, who had been appointed by Manson as helminthologist at the London School of Tropical Medicine, to Africa to investigate this problem (Leiper, 1913). The search for the intermediate stages in the life cycle of schistosomes took a long time and it was not until 1915 that Leiper demonstrated the complete life cycles in their snail hosts and established that were two species that had different intermediate hosts: the terminal-spined egg, $S$. haematobium, transmitted by snails of the genus Bulinus, and the lateral-spined egg, S. mansoni, transmitted by snails of the genus Planorbis (Leiper, 1916). The third important species, S. japonicum, had been discovered by Fujiro Katsurada in 1904 and its development in the snail host had been described by Miyairi and Suzuki (1913) 2 years before Leiper independently described the life cycle of $S$. haematobium. Unfortunately for Leiper, the Japanese workers published their findings in Japanese journals that were not available outside Japan and Leiper was unaware of their findings until he had made his own discoveries.

The paper by Russell Stothard et al. (2017) is concerned with the work of Robert Leiper particularly his mandate in Egypt in 1915 to prevent and break transmission of this disease in British troops. This he did by implementing simple water hygiene measures largely applicable to military conditions, at that time, unfortunately out of reach for the millions of Africans living in poverty. The paper by Stodhard et al. celebrates the centenary of Leiper's original research achievements and focuses on schistosomiasis in Uganda and discusses the reasons why 
expanded access to treatment with praziquantel is needed now and introduces, COUNTDOWN, an implementation research consortium funded by DFID, UK, which fosters the scale-up of interventions (Stothard et al. 2017).

\section{PAEDIATRIC SCHISTOSOMIASIS}

Continuing the theme of schistosomiasis after Leiper, Amaya Bustinduy et al. consider the problem of paediatric schistosomiasis (Bustinduy et al. 2017). As in other areas of parasitology, the problem was acknowledged first with respect to British military and civil servants living in the tropics and only later the native populations. In 1890s the British Council recommended that British children should be sent home in order to avoid the consequences of bilharzia (schistosomiasis) (Farley, 1991) but very little happened for the next 20 years until tartar emetic was introduced as a treatment for the disease and later a number of other drugs were used before the introduction of praziquantel and its widespread use since 1984. Praziquantel revolutionized the treatment of children and in 2001 the World Health Assembly initiated a schistosomiasis school-based control programme to promote child health and cognitive improvement. In 2011 the Praziquantal Consortium was charged with the task of formulating doses of the drug suitable for children under the age of 6 . The key intervention involved school-based mass drug administration but success has been very patchy and, although over 123 million children in 52 countries require preventive treatment, only 43 million actually receive it. The authors conclude that while mass drug administration lowers the prevalence of schistosomiasis there is considerable residual morbidity and the persistence of low level worm burdens hinder plans for the elimination of the disease in many areas and that there is a need for better strategies for control.

\section{SCHISTOSOMIASIS CONTROL IN ZIMBABWE}

The paper by Francisca Mutapi considers schistosomiasis control with particular reference to Zimbabwe (Mutapi, 2017). Schistosomiasis was probably endemic in Zimbabwe before colonization and, as elsewhere, control of this disease was primarily directed towards the health of British military and officials. This attitude changed in the 1920 s when it was realised that, although schistosomiasis, particularly in European children, was under control, there was still the possibility of acquiring the infection from the indigenous population. It took some time before treatment, with a variety of drugs, most recently praziquantel, was extended to all children largely as a result of the establishment of specialized laboratories, the Blair Institute in Salisbury (now Harare) and the De Beers Research Laboratory in Chiredzi. In addition to drug treatment, parallel strategies advocated by the Water, Sanitation and Hygiene WASH) scheme include the use of molluscicides, biological vector control, engineering projects relating to irrigation and dams and improvements in the provision of safe water and sanitation and the availability of latrines and toilets built from local materials Zimbabwe's commitment to schistosomiasis research and control has resulted in ongoing projects such as a 5-year national schistosomiasis and soil transmitted helminths campaign in 2012 the results of which have yet to be evaluated but do seem to be promising.

\section{SCHISTOSOMIASIS AND RESERVOIR HOSTS IN} CHINA

In a previous paper, Russell Stothard et al gave a brief account of Robert Leiper's expedition, with Howard Atkinson, to China to study the transmission of the Asian schistosome, Schistosoma japonicum (Stothard et al. 2017). One of the significant outcomes of this expedition was the realization of the importance of dogs and other animals as hosts of $S$. japonicum, a finding that is now, nearly a century later, the subject of the paper by Van Dorssen et al. in this issue (2017). Leiper paid little attention to the role of animal reservoirs in the control of $S$. japonicum but it is now known that about 46 species of mammal can harbour the infection and, of these, water buffalo, cattle, sheep, goats, horses, pigs, dogs, cats and rodents are all significant reservoir hosts. The reduction of schistosomiasis in the People's Republic of China (PCR) has been one of the success stories of this century but there are still 286000 people infected and 60 million at risk with major foci round Lakes Dongting and Poyang in Hunan Province. Control has largely been achieved by a combination of mass chemotherapy with praziquantel of humans and bovids, snail control, environmental modification, improved sanitation, better latrines, health education and the relocation of bovids, all except the last would have been logical extensions of Leiper's work in Asia. There is still, however, a need to understand more about the role of mammals other than bovids and the paper by Van Dorrsen et al. in this issue is concerned with the prevalence of $S$. japonicum particularly in rodents, dogs and goats but also in water buffalo and cattle in the Dongting Lake area in Hunan Province of China (Van Dorssen et al. 2017). The team had a range of techniques available including traditional coproparasitological and others that Leiper could never have envisaged such as molecular techniques, which were more sensitive than the traditional methods and the team found that the prevalence of $S$. japonicum in goats was higher than previously recorded and recommended that goats should be included as targets for control of Asian schistosomiasis. 


\section{GUINEA WORM}

Robert Leiper is best known for his work on schistosomiasis but he played an equally (some would say, more) important role in determining the life cycle of the Guinea worm, Dracunculus medinensis, a parasite described in the Bible and in the earliest literature. Adult female worms containing larvae had been known since the beginning of the 19 th century and over the next few years it was thought that humans became infected through the skin, as had been shown for hookworms. In 1870 the Russian scientist, Aleksej Pawlowich Fedchenko, implicated small crustaceans of the genus Cyclops in the life cycle and succeeded in infecting them with Dracunculus larvae and suggested that humans and other animals acquired their infections by accidentally consuming the infected crustaceans (Fedchenko, 1870). Fedchenko was unsuccessful in his attempts to infect dogs so his discoveries were controversial and remained so until the problem was taken up again by Manson in 1894 who had succeeded in infecting Cyclops from a local pond in London. He was not, however, able to pursue this line of investigation but nevertheless maintained his interest in the subject and in 1905 persuaded his protégee, Robert Leiper, then working in the Gold Coast (Ghana) to carry on from where he had left off. Leiper repeated Manson's (and Fedchenko's) experiments and showed that when the infected crustaceans were exposed to acid they dissolved but that the worm larvae remained alive and escaped into the surrounding fluid (Leiper, 1906). Leiper suspected that this might be what happened in the human stomach and eventually succeeded in infecting monkeys with infected crustaceans and thus conclusively demonstrated that humans could become infected by accidentally drinking contaminated water. Based on these observations he advocated a number of control policies, including avoidance of contaminated drinking water or filtering it, and these preventive measures have paved the way for further research. A serious challenge to eradicate Guinea worm disease was taken up about seven decades later and this is the subject of the paper by Ahmed Tayeh et al. who described programmes sponsored by the World Health Organization, the Centers for Disease Control, the Carter Foundation and other organizations that have reduced the number of cases from $3 \cdot 5$ million in 1986 to 22 in 2016 with the expectation that this will eventually lead to the eradication of the disease (Tayeh et al. 2017).

ROBERT LEIPER AND THE LONDON SCHOOL OF TROPICAL MEDICINE

A completely different aspect of Robert Leiper's work is described by Francis Cox (Cox, 2017b). Leiper's scientific work with schistosomiasis and Guinea worm disease up to about 1915 has been extensively reviewed in this issue (see Stothard et al. 2017;
Tayeh et al. 2017) but what he did next is rarely mentioned. Leiper was appointed helminthologist at the London School of Tropical Medicine (LSTM) in 1905 and for the first years of his career he had modest teaching duties and plenty of time for research and achieved considerable success, as has been described in other papers in this Symposium, but in 1920 he turned his attention to the need for education and training in the field of tropical diseases and had grandiose plans for an Imperial School of Hygiene involving the LSTM University College London and King's College, London. These plans unfortunately could not be fulfilled but Leiper persisted with the idea of an institute of public health in London and in 1922 persuaded the Rockefeller Foundation to purchase a site in Bloomsbury for what had then become the London School of Hygiene and Tropical Medicine (LSH\&TM). Work on the new institution began in 1926 and it opened in 1929. Leiper's next ambitious plan was to establish an Institute of Animal Parasitology at a site, Winches Farm, St Albans in Hertfordshire about 20 miles north of the LSH\&TM, with himself as Director. Under Leiper's direction, Winches Farm became a centre of excellence for research on helminths of economic importance and plant and insect pests and attracted a number of distinguished parasitologists whose work continued until 1992, 70 years after Leiper first envisaged this project.

Leiper, who had been interested in bibliography since his teens, now had an opportunity to contribute to the literature of helminthology and, in 1923, he launched the Fournal of Helminthology which he edited for nearly 25 years. In 1932 he was instrumental in establishing Helminthological Abstracts and, in 1977, its sister abstracting journal, Protozoological Abstracts, publications that have been invaluable to generations of research and field helminthologists and protozoologists. Robert Leiper continued to work up to the time of his death in 1969.

\section{DAVID LIVINGSTONE}

No account of the contributions made by Scottish physicians and scientists would be complete without some mention of the explorer, David Livingstone. David Livingstone's name did not appear in the pantheon in the paper by Cox (2017a) mainly because he was not recognized for making any ground-breaking discoveries in the field of tropical diseases. He did, however, in the course of his expeditions, have many encounters with tropical diseases, which he recorded in some detail and thus contributed to our understanding of the nature of several tropical disease and justified his inclusion in this Special Issue. Livingstone was born in 1813 and educated at Anderson's University in Glasgow (the predecessor of Strathclyde University) where he read medicine and prepared for a life as a missionary. He spent 30 years trekking 
across Southern Africa during which time he encountered a number of tropical diseases that are described in a paper by Barrett and Giordani in this Special Issue (Barrett and Giordani, 2017). Livingstone was a meticulous observer and he recorded, in some detail, his experiences with a wide range of tropical infections including hookworm, schistosomiasis, trichiuriasis, elephantiasis, loiasis, malaria, leprosy, relapsing fever and yellow fever in humans and nagana in cattle. Well ahead of his time he suspected that many of these diseases were transmitted by vectors. Although he did not report on any cases of human trypanosomiasis he was very much interested in nagana in cattle and even suggested that it was transmitted by tsetse flies some 40 years before Bruce demonstrated the fly transmission of trypanosomes. David Livingstone died in May 1873 leaving behind a chronical of his travels and the diseases he had encountered that were not only invaluable to future historians but actually encouraged a generation of ambition Scots to go and seek the causes of tropical diseases.

\section{Concluding remarks}

The contributions to tropical medicine by the Glaswegian scientists and physicians were mainly the establishment and confirmation of the life cycles of important parasites in their human and vector hosts. Without this knowledge it would have been impossible to devise ways to control these diseases. Those who made these discoveries over a century ago probably imagined that with their knowledge of the life cycles, and knowledge as how to control these diseases, that eradication would have been easily achievable. They could never have guessed that diseases such as schistosomiasis and Guinea worm disease would still be prevalent in the 21 st century. The papers in this Symposium describe how the life cycles of important parasitic diseases such as schistosomiasis and Guinea worm disease were unravelled and what is now being done to eliminate their ravages. The contributions made by Muriel Robertson, William Leishman and Robert Leiper deserve to be remembered and this Symposium is a lasting tribute to their achievements.

\section{REFERENCES}

Barrett, M. P. and Giordani, F. (2017). Inside Doctor Livingstone: a Scottish icon's encounter with tropical diseases. Parasitology. doi: 10.1017/S003118201600202X.
Bilharz, T. (1853). Fernere Mittheilungen über Distoma haematobium. Zeitschrift für Wissenschlaftliche Zoologie 4, 454-456.

Bruce, D. (1894). Preliminary Report on the Tsetse Fly Disease or Nagana in Zululand. Bennett and David, Durban, South Africa.

Bruce, D. (1915). Croonian lectures. British Medical fournal i, 1073-1078. Bustinduy, A. L., Wright, S., Joekes, E. C., Kabatereine, N. B., Reinhard-Rupp, J., King, C. H. and Stothard, J.R. (2017). One hundred years of neglect in paediatric schistosomiasis. Parasitology. doi: 10.1017/S0031182017000014.

Cox, F.E.G. $(2017 a)$. The golden age of parasitology-1875-1925: the Scottish contributions. Parasitology. doi: 10.1017/S0031182016001566.

Cox, F. E. G. (2017b). Robert Leiper and the London School of (Hygiene and) Tropical Medicine. Parasitology. doi: 10.1017/S0031182016002079.

Donovan, C. (1903). On the possible occurrence of trypanosomiasis in India. British Medical fournal 2, 79.

Farley, J. (1991). Bilharzia. A History of Imperial Tropical Medicine. Cambridge University Press, Cambridge, UK.

Fedchenko, A.P. (1870). Concerning the structure and reproduction of the Guinea Worm Filaria medinensis [translated from the Russian]. American Journal of Tropical Medicine and Hygiene 20, 511-523.

Hammarton, T. C. (2017). The remarkable Dr Robertson. Parasitology. doi: $10.1017 / \mathrm{S} 0031182016002080$.

Hoare, C. A. (1972). The Trypanosomes of Mammals. Blackwell Scientific Press, Oxford, UK.

Leiper, R. T. (1906). The influence of acid on Guinea worm larvae encysted in Cyclops. British Medical Fournal i, 19-20.

Leiper, R. T. (1913). Report to the advisory committee of the tropical diseases research fund colonial office London. Tropical Diseases Bulletin 2, 195-196.

Leiper, R. T. (1916). On the relation between the terminal-spined and lateral-spined eggs of bilharzia. British Medical fournal i, 411.

Leishman, W. B. (1903). On the possibility of the occurrence of trypanosomiasis in India. British Medical fournal i, 1252-1254.

Miyairi, K. and Suzuki, M. (1913). [On the development of Schistosoma japonicum. In Japanese]. Tokyo Iji Shinshi 1836, 1-5.

Mutapi, F. (2017). Getting a GRiPP on everyday schistosomiasis: experience from Zimbabwe. Parasitology. doi: 10.1017/ S0031182016001724.

Robertson, M. (1912). Notes on the polymorphism of Trypanosoma gambiense in the blood and its relation to the exogenous cycle in Glossina palpalis. Proceedings of the Royal Society B 85, 527-539.

Robertson, M. (1913). Notes on the life-history of Trypanosoma gambiense, with a brief reference to the cycles of Trypanosoma nanum and Trypanosoma pecorum in Glossina palpalis. Philosophical Transactions of the Royal Society B 203, 161-184.

Ross, R. (1903). Notes on the bodies recently described by Leishman and Donovan. British Medical Fournal ii, 1261.

Ross, R. and Thompson, D. (1911). A case of sleeping sickness studied by precise enumerative methods: regular periodic increase of the parasites disclosed. Proceedings of the Royal Society B 82, 411-415.

Stothard, J. R., Kabatereine, N. B., Archer, J., Al-Shehri, H., TchuemTchuente, L. A., Gyapong, M. and Bustinduy, A. L. (2017). A centenary of Robert T. Leiper's lasting legacy on schistosomiasis and a COUNTDOWN on control of neglected tropical diseases. Parasitology. doi: 10.1017/S0031182016000998.

Tayeh, A., Cairncross, S. and Cox, F. E. G. (2017). Guinea worm: from Robert Leiper to eradication. Parasitology. doi: 10.1017/ S0031182017000683.

Van Dorssen, C. F., Gordon, C. A., Li, Y., Williams, G. M., Wang, Y., Luo, Z., Goibet, G. N., You, H., McManus, D. P. and Gray, D. J (2017). Rodents, goats and dogs - their potential roles in the transmission of schistosomiasis in China. Parasitology. doi: 10.1017/ S0031182017000907.

Vickerman, K. and Luckins, A. G. (1969). Localization of variable antigens in the surface coat of Trypanosoma brucei using ferritin conjugated antibody. Nature (London) 224, 1125-1126.

Vincent, H. (2017). William Boog Leishman: parasitologist and politician. Parasitology. doi: 10.1017/S0031182016001657. 